Pedagogía y Saberes n. ${ }^{\circ} 52$

Universidad Pedagógica Nacional

Facultad de Educación. 2020. pp. 77-92

\title{
El arte del hacer en la enseñanza de las ciencias sociales y la historia*
}

Artículo de investigación

The Art of Doing in Teaching Social Sciences and History A arte de fazer no ensino de ciências sociais e história

Diego H. Arias Gómez**

Para citar este artículo:

Arias, D. (2020). El arte del hacer en la enseñanza de las ciencias sociales y la historia. Pedagogía y Saberes, 52, 77-92. DoI: https:// doi.org/10.17227/pys.num52-10289

* El presente artículo es resultado de la investigación titulada "Perspectivas docentes sobre enseñanza de la historia reciente en Colombia”, código: 4-155-533-16, financiada por el ciDc de la Universidad Distrital Francisco José de Caldas.

** Profesor de la Universidad Distrital Francisco José de Caldas. Doctor en Educación de la Universidad Pedagógica Nacional e investigador del Grupo Educación y Cultura Política.

Correo electrónico: dhariasg@udistrital.edu.co

Código ORCID: http://orcid.org/0000-0002-0116-0896 


\title{
Resumen
}

El presente escrito busca contribuir a la conceptualización sobre la enseñanza de lo social y lo histórico en el país. En concreto, se resalta la especificidad de este tipo de saber en la educación básica y media; así, un saber escolar y una práctica escolar confluyen en la enseñanza de las ciencias sociales, cuya naturaleza, método y objetivos distan de las disciplinas científicas que con frecuencia le reclaman paternidad. Para responder a este itinerario, en primera instancia, se insinúan algunos momentos clave en la historia de la enseñanza de las ciencias sociales en Colombia, como telón de fondo para llegar, en un segundo momento, a la conceptualización del conocimiento escolar como un saber específico producido y pensado para la escuela, del cual bebe la teorización sobre enseñanza de la historia. Finalmente, se presentan algunas características del tipo de quehacer propio de la enseñanza de las ciencias sociales y la historia acompañados de relatos docentes y seguidos de un breve cierre a manera de colofón.

\section{Palabras clave}

enseñanza de las ciencias sociales; enseñanza de la historia; ciencias sociales escolares; educación social; escuela

\begin{abstract}
The present paper seeks to contribute to the conceptualization of the teaching of the social and the historical in the country, specifically highlighting the specificity of this type of knowledge in basic and secondary education; thus, school knowledge and school practice converge in the teaching of social sciences, whose nature, method and objectives are far from the scientific disciplines that often demand paternity. To respond to this itinerary, in the first instance, some key moments in the history of social science teaching in Colombia are suggested as a backdrop to reach, in a second moment, the conceptualization of school knowledge as a knowledge specific produced and thought for the school, from which drinks theorization about history teaching; finally, we arrive at the thesis of the paper where some characteristics of the type of work typical of the teaching of social sciences and history are presented, accompanied by teacher stories and followed by a brief closing as a colophon.
\end{abstract}

\section{Keywords}

social sciences teaching; history teaching; school social sciences; social education; school

\section{Resumo}

O presente trabalho busca contribuir para a conceituação do ensino do social e do histórico no país, destacando especificamente a especificidade desse tipo de conhecimento no ensino fundamental e médio; Assim, o conhecimento e a prática escolar convergem para o ensino das ciências sociais, cuja natureza, método e objetivos estão distantes das disciplinas científicas que frequentemente exigem paternidade. Para responder a esse itinerário, em primeiro lugar, sugerem-se alguns momentos-chave da história do ensino das ciências sociais na Colômbia como pano de fundo para alcançar, em um segundo momento, a conceituação do conhecimento escolar como conhecimento específico produzido e pensado para a escola, a partir do qual bebe a teorização sobre o ensino da história; finalmente, chegamos à tese do artigo, onde são apresentadas algumas características do tipo de trabalho típico do ensino de ciências sociais e história, acompanhadas de histórias educacionais e seguidas de um breve fechamento como ponto culminante.

\section{Palavras-chave}

ensino de ciências sociais; ensino de história; ciências sociais da escola; educação social; escola 
La educación es rica en prescripciones y pobre en descripciones. No hay lugar donde esto sea más evidente que en el caso de los dos millones de personas que imparten clases en las escuelas públicas. Por lo general se acepta que la transacción fundamental de la educación se produce en el lugar donde se encuentran profesores y alumnos. [...] Pero aunque existen multitud de libros y artículos que dicen al profesorado cómo debe comportarse, los estudios empíricos sobre el trabajo de los enseñantes (y sobre quienes componen las planillas de las escuelas) siguen siendo escasos.

Lortie (1975, citado por Goodson, 2004, p. 47).

\section{Introducción}

I as ciencias sociales y la historia escolares en Colombia han entrado a debate en los últimos meses gracias a dos importantes hechos noticiosos: el engavetado proyecto de ley del Senado sobre limitaciones a la libertad de cátedra y la información en redes sociales, acerca de cómo aparece la política de seguridad democrática en algunos libros de texto de reputadas editoriales.

Ambos hechos han puesto de manifiesto el carácter polémico que siempre han representado los contenidos en la escuela, especialmente los ligados a las ideas políticas, por cuenta del deseo de regular lo que en ella circula, pero también, la vieja sospecha que ciertos sectores guardan hacia los maestros de esta área, ahora revestidos como adoctrinadores y pervertidores de las conciencias de las nuevas generaciones o replicadores ciegos de lo que dicen los libros de texto.

El presente escrito busca contribuir a la reflexión sobre la enseñanza de lo social y lo histórico en el país; en concreto, se resalta la especificidad de este tipo de saber en la educación básica y media, profundizando en que también es un tipo de quehacer; así, un saber escolar y una práctica escolar confluyen en la enseñanza de las ciencias sociales cuya naturaleza, método y objetivos distan de la lógica de las disciplinas científicas que con frecuencia le reclaman paternidad. Para responder a este itinerario, en primera instancia, se insinúan algunos momentos clave en la historia de la enseñanza de las ciencias sociales en Colombia, como telón de fondo para llegar, en un segundo momento, a la conceptualización del conocimiento escolar como un saber específico producido y pensado para la escuela, del cual bebe la teorización sobre enseñanza de la historia; finalmente se llega a la tesis del escrito donde se presentan algunas características del tipo de quehacer propio de la enseñanza de las ciencias sociales y la historia, seguidos de un breve cierre a manera de colofón.

\section{Fragmentos históricos sobre la enseñanza de la historia y las ciencias sociales}

Históricamente es posible rastrear la manera como el saber sistematizado referido a lo sociopolítico e histórico en América Latina fue elaborado inicialmente como material escolar, por lo menos en casi todo el siglo XIX y los inicios del Xx. Así lo constata para Argentina Silvia Finocchio (2010), con los manuales patrios utilizados para argentinizar a la población ante la urgencia de unificar diferentes lenguas y nacionalidades; María Schmith (2000) para Brasil, con la importancia de la difusión del sentimiento nacionalista para ese país, y para el caso chileno, Sol Serrano (2014), aunque no tanto vinculada a la identidad nacional, quien indica que la enseñanza de la historia priorizó la formación ciudadana desde el escenario escolar.

Para el caso colombiano, son conocidas las tesis de Alejandro Álvarez (2013), quien afirma que pseudohistoria escrita durante el siglo XIX obedeció a la estructura de crónicas que narraban fragmentariamente episodios puntuales para inflamar el sentimiento patrio y cuyos destinatarios eran fundamentalmente los escolares. Para el autor, "el patriotismo que se procuraba acudía a los recursos que les eran propios a las lecciones religiosas o de moral, por eso los textos y manuales escolares se llamaron también catecismos" (p. 37). Según Álvarez (2013), la enseñanza de la historia precedió por muchos años la configuración en el país de la disciplina histórica, que habrá de esperar los principios del siglo $\mathrm{xx}$ para dar sus primeros pasos al calor de varios hechos: la influencia de los ideales positivistas, la crisis ocasionada por la guerra de los Mil Días y la separación de Panamá, y la imperiosa necesidad de las élites de construir un relato unificado y glorioso del pasado nacional. Así, agrega el autor, la búsqueda de cientificidad de la historia se tradujo en 1902 con la creación de la Academia de Historia y Antigüedades Colombianas, más adelante llamada Academia Colombiana de Historia.

La Academia, señala Sandra Rodríguez (2017), fungió por muchas décadas como órgano consultivo del Gobierno nacional en asuntos históricos, específicamente en la producción de textos oficiales para la enseñanza escolar y en la ocupación de cargos 
oficiales de sus representantes como directores de instrucción pública. En este sentido, para la autora, la narrativa que impone la Academia en gran parte del siglo XX estuvo marcada por cuatro ejes:

La selección de contenidos específicos en los planes de estudio y los textos escolares (lo que se debe enseñar), la construcción de una propuesta pedagógica basada en la ejemplaridad (lo que se debe saber y recordar), la reglamentación de una liturgia escolar para celebrar los festejos patrióticos mediante el ejemplo cívico (lo que se debe conmemorar), y la corrección o exclusión de contenidos y temáticas que puedan alterar los principios de la nacionalidad (lo que se debe olvidar). (pp. 302-303)

Dicha iniciativa tuvo un fugaz intento de contención en la república liberal de la década de 1930 y principios de la de 1940, no solo vigente para los libros de texto sino para la formación docente, los índices de matrícula y otros aspectos del precario sistema educativo de entonces. En los años posteriores a 1948, la Academia tuvo un nuevo ímpetu en el sentido de desmontar la propuesta pedagógica de los gobiernos liberales y retomar la tradición, "que, según Rafael Azula Barrera, segundo ministro de Educación de Laureano Gómez y miembro correspondiente de la $\mathrm{ACH}$, había sido 'fría y hábilmente deformado en las últimas décadas por un híspido y corrupto materialismo'" (Rodríguez, 2017, p. 380).

Como último referente para estos rodeos históricos sobre la enseñanza de las ciencias sociales y la historia, Mireya González (2012) informa que entre las décadas de 1960 y 1990 se transitó por el reino de la ciencia y el desarrollo, en el que el rol del Estado se centró en los contenidos y las metodologías por medio de la formulación de planes de estudio para optimizar el control del ejercicio docente. Para la autora, el Estado también "compartió la inspección sobre los textos escolares con la Academia Colombiana de Historia y se desentendió, casi completamente, de la formación inicial de docentes, pues esta quedó en manos de las nacientes facultades de educación" (p. 68).

Según González, desde 1990 hasta la primera década del 2000, se vive una crisis de discursos referidos al saber, los sujetos y las instituciones encargados de la enseñanza de lo social e histórico en Colombia, expresados en la confrontación entre ideales morales, identitarios, sentimentales y patrióticos de la asignatura, por un lado, y la función científica y de formación del pensamiento, por otro; en este último componente caben los conocimientos disciplinares y las competencias para el mercado. Además, en los últimos años, dice la autora, la enseñanza de la historia es complejizada por la propia dinámica que sufrieron las ciencias sociales en general, en el sentido que no solo otros saberes distintos al histórico son convocados al aula, sino que nuevas y viejas problemáticas sociales y políticas son objeto de atención educativa, algunas de las cuales se vuelven cátedras, contenidos transversales o temas obligantes. Para González (2012), el nuevo profesor, supuestamente necesario para esta nueva amalgama de conocimientos, debía reunir demasiadas condiciones:

El saber pedagógico toma forma a través de los sujetos de la enseñanza, y a la vez ellos se han configurado en su relación con el saber de diversas formas: como habilidosos artesanos cuidadores de su oficio que pacientemente tejían los relatos sobre la historia; expertos planeadores que dosifican y proponían un ordenamiento "lógico" a los contenidos de la historia; trabajadores culturales incansables que se ocupan de mediar entre la historia "científica" y la historia "popular"; facilitadores que acondicionan los ejes curriculares o las preguntas problematizadoras para administrar un currículo; el investigador que hace de la ciencia social su práctica de enseñanza; el intelectual que hace consciencia de su condición histórica y la vuelve el eje de su crecimiento, o el profesional al que se le pide ser competente en los asuntos a su cargo. (p. 71)

Falta en estos saltos por el tiempo hacer mención a la influencia de la Nueva Historia en la enseñanza de las ciencias sociales en las décadas de 1970 y 1980 (Arias, 2015), y quizá a la propia transformación que tuvo la enseñanza de la geografía en el país, que ha transitado un camino propio que no necesariamente corresponde el de las otras ciencias sociales, aspectos que el presente escrito no alcanza a tratar.

\section{La enseñanza de las ciencias sociales como saber y quehacer escolares}

En el marco del anterior recorrido histórico se justifica presentar la enseñanza de las ciencias sociales como un saber y una práctica escolar particular, en el sentido de ser considerado un producto específico de la dinámica escolar. Debemos al Grupo de Historia de la Práctica Pedagógica una larga puja por reivindicar el saber pedagógico más allá de las pesquisas científicas y de los pruritos disciplinares. Según Saldarriaga (2006) la sutil subordinación de los maestros a los expertos es de vieja data, y tiene que ver con el gobierno de las epistemologías científicas 
modernas desde el siglo XVI en adelante, pasando por los humanistas del Renacimiento, que asignaron a la escuela el papel de reproducir ciertos procedimientos propios de las disciplinas científicas, en el marco de la clásica división social del trabajo aplicado al conocimiento. Pese al paso de los tiempos y los avances pedagógicos, conceptuales y tecnológicos, para el autor, la estructura escolar sigue inalterada, pues "los formatos de la organización cotidiana de la escuela -tiempos, espacios, disciplina, número de alumnos por profesor, encierro de los salones, uniformes y trajes, autoridad jerárquica, etc.- se han mantenido prácticamente estáticos desde las épocas de su diseño original" (p. 62).

Así, se le endilgó a la escuela el secundario lugar de aplicación de la teoría, esta última generada en otros espacios y por personas eruditas, de aquí la primera culpabilización al maestro como intelectual fallido. La segunda culpabilización, según Saldarriaga (2006), viene del espíritu experimental de la ciencia moderna, que anuncia que en la escuela se experimenta con un saber duro, ajeno a ella, en la que la pedagogía debe ser entendida a lo sumo como una destreza técnica para aplicar en la enseñanza. Dicha vertiente se refuerza en algunos países latinoamericanos, incluida Colombia, en la que la escuela pública nace originalmente como lugar de confinamiento para los sectores más excluidos de la sociedad (Martínez, 2008). La escuela es vista históricamente como una institución que, aunque necesaria, carga con el doble estigma de albergar cierto marginamiento social: la versión deformada del conocimiento científico, y el desprecio o, por lo menos, la sospecha hacia las posibilidades de los sujetos que la habitan.

Respecto al conocimiento social e histórico que la escuela imparte, Raimundo Cuesta (2002) considera que estos, así como otros conocimientos elaborados por y para la escuela, han de ser desnaturalizados en su construcción y circulación social. Según el autor, la asignaturización del saber obedece a un proceso sociohistórico "que tiende a jerarquizar el conocimiento y a conceder un reparto de papeles entre quien sabe los "misterios" de la asignatura (el profesor, que ya la recibe hecha por sus colegas universitarios) y quien, no sabiendo (el alumno), aspira a conocerlos en un lejano día" (p. 222).

De manera que el conocimiento por disciplinas es un rasgo básico del saber escolar, cuya relación con las disciplinas científicas es dinámico y en ocasiones contradictorio. La historia social de las disciplinas escolares alerta sobre la improcedencia de conceptos como transposición didáctica (Chevallard, 1997) o mera reproducción del saber (Bourdieu y Passeron,
2001), en los que desde distintas tradiciones de la sociología del currículo le asignan al saber escolar un lugar subsidiario de las disciplinas científicas, en tanto en el aula solo de adapta o de duplica lo que en otros sectores se factura con mucho mayor nivel. Para Cuesta (2002),

[...] las disciplinas escolares constituyen conjuntos culturales originales que pugnan por ocupar, con diversos apoyos y estrategias sociales, nichos curriculares en donde asentarse y perpetuarse en tradiciones discursivas y prácticas. Son, en efecto, construcciones sociohistóricas, esto es, tradiciones sociales inventadas históricamente, que forman parte esencial del conocimiento escolar y que, por sus rasgos peculiares, propenden a durar en forma de estereotipos de pensamiento y de acción. Por estas razones, la historia o cualquier otra disciplina que se imparte en los establecimientos de enseñanza obedece a una lógica sui géneris que se encuentra profundamente unida al carácter y función social que desempeña la escuela dentro de la evolución del capitalismo en sus diversas fases. (p. 225)

Por ello, para el autor, contra algunos estereotipos, lo que sucede en la escuela no es una vulgarización de la ciencia, sino un tipo de saber con un estatuto propio, dada su naturaleza, metodología y destinatarios. Es una creación social pensada y practicada en función del intercambio específico entre profesores y estudiantes. Cuesta (evocando a Kliebard) afirma que la asignatura escolar se ha visto sometida a tres grupos de opinión cuya intersección y fuerza varía en cada país: los humanistas, defensores de la cultura clásica y las disciplinas tradicionales; los eficientistas, ligados a la versión pragmática de la ciencia y el beneficio económico; y los igualitaristas, defensores del ascenso social que posibilita la escuela. De allí que el significado cultural de las ciencias sociales escolares no puede ubicarse solo en las políticas educativas, los planes de estudio, las ideas de prestantes pedagogos o los libros de texto, sino en los caminos intrincados y desconocidos de las prácticas de enseñanza.

En este marco, el autor instaura el término de código disciplinar, para referirse al "conjunto de ideas, valores, suposiciones, reglamentaciones y rutinas prácticas (de carácter expreso o tácito). En suma, el elenco de ideas, discursos y prácticas dominantes en la enseñanza de las materias de enseñanza dentro del marco escolar" (p. 231). Este código contempla los discursos, los contenidos y los modelos de práctica docente considerados válidos y legítimos, que interaccionan y se transforman "impelidos por los usos sociales característicos de las instituciones escolares" (p. 231). 
La categoría código disciplinar, si bien tiene la potencia heurística para entender las razones por las que en determinados momentos de la historia las ciencias sociales escolares estuvieron jalonadas por ideales patrioteros, románticos y nacionalistas, como se observó en el primer apartado, y también por discursos eugenésicos, racistas y cristianizantes (Herrera, Pinilla y Suaza, 2003) propios de décadas pasadas, alerta sobre la importancia de rastrear los consumos y las construcciones de conocimiento en el aula, sobre lo que poco hay evidencias. Así como hoy se comprende la incidencia de las fuerzas globalizadoras de finales del siglo xx en función de perspectivas cosmopolitas, holísticas y retóricamente respetuosas de los derechos humanos y el medio ambiente, vale la pena un acercamiento a sus dinámicas y concreción en el salón de clases. Aunque la escuela no es ajena las modas sociopolíticas, ellas se ponderan a partir de documentos, normas, registros de planes oficiales y biografías de los docentes que llevan al aula este saber. De este conjunto se sigue con pocos datos alusivos a las prácticas escolares. Hay argumentos para pensar que en muchas aulas imperan las rutinas y la cultura escolar por años asentada. Ejemplo de ello es el panorama de los últimos veinte años respecto a la vieja nominación de objetivos transmutada luego en logros, indicadores, desempeños y en ahora en competencias, cuyo cambio en los títulos parece que poco afectó las prácticas escolares (Vasco, 2003).

El código disciplinar, aunque subraya el carácter refractario de la realidad educativa en el sentido de ser relativamente impermeable a los influjos externos, también posiciona el saber y la práctica docente a otro nivel del considerado por las políticas educativas y el saber académico, que infantiliza lo que produce la escuela como deformado y deficitario, y por tanto, objeto de intervención, vigilancia, evaluación y monitoreo. También recusa las elaboraciones conceptuales que expertos hacen para que los profesores de educación básica y media apliquen o adapten lo que ellos conciben. La capacidad de agencia de los docentes allí no es reconocida, quienes han de recrear los estándares y conocimientos básicos que especialistas han hecho para el supuesto beneficio de sus escuelas. El código disciplinar se convierte en una herramienta política para reivindicar la capacidad del profesor como intelectual de la educación (Giroux, 1988) y no como operario del conocimiento al que diferentes lógicas le quieren reducir.

Por otra parte, la preocupación por la comprensión del código disciplinar revela la importancia de las prácticas escolares, que saca a la luz las accio- nes ordinarias poco controladas de los entornos educativos. María Paula González (2018) plantea la distancia existente entre las normativas y las prácticas escolares no como un asunto de deformación sino como la manera de reconocer un ámbito de la realidad distinto, en el que la práctica corresponde a "los gestos, comportamientos y afectos, así como a las emociones, las ideas, representaciones, significaciones y apropiaciones. Es decir, pensar las prácticas como 'artes de hacer' tal como propuso Michel de Certeau" (p. 12). Para la autora, las prácticas ordinarias difícilmente se prestan para establecer modelos, pues en lo cotidiano irrumpen muchos imprevistos y situaciones que cuestionan las tradicionales lógicas que delimitan el saber teórico. En esta línea, el docente de ciencias sociales realiza una práctica activa de apropiación de un conjunto de factores: normas, diseños curriculares, discursos didácticos, saberes académicos, coyunturas políticas y opciones personales, en y para el aula, así "se producen saberes y prácticas oportunas, situadas, contingentes" (p. 34). Para la pedagoga argentina, los docentes negocian día a día un margen de juego que habilita la heterogeneidad regulada de los quehaceres posibles, en que las prácticas consisten en gestos y palabras autorizadas para ser producidas en el aula, "con lo que cada uno evalúa empíricamente como satisfactorio, esto es, con lo realizable en el aquí y el ahora de la clase" (Chartier, citada por González, 2018, p. 34).

De esta forma se produce una tensión entre lo deseado y lo posible, entre lo prescrito y lo realizado, entre lo que la ley o la institución ordena o el deber ser y lo que realmente se hace en el aula, cosa que se ejemplifica con los conceptos "decerteaunianos" de tácticas y estrategias. La estrategia vendría a ser el componente estructural que presiona para que determinado tipo de palabras y comportamientos reinen en la clase de ciencias sociales. Este nivel estratégico es agenciado por las políticas educativas, las modas didácticas y los expertos que representan las estrategias del poder, que invierten importantes recursos económicos y simbólicos para definir el quehacer docente. Pero, por su parte, la táctica encarna el carácter productivo del uso que el docente hace de aquellos dispositivos, pues si bien no cuenta aparentemente con algo propio

[...] es una victoria del lugar sobre el tiempo [...]. Necesita constantemente jugar con los acontecimientos para hacer de ellos "ocasiones". Sin cesar el débil debe sacar provecho de fuerzas que le resultan ajenas. Lo hace en momentos oportunos en que combina elementos heterogéneos. (De Certeau, 1990, p. L) 
Las tácticas son las maniobras y formas que el docente ejecuta con los elementos que toma del medio para la puesta en escena de su clase. Es el arte del hacer, en el que el docente materializa el margen de acción que le queda frente a las fuerzas que consciente o inconscientemente lo constriñen.

En síntesis, la peculiaridad de la enseñanza de las ciencias sociales se define por un saber y un quehacer escolares que la docente porta y ejecuta, y que, como se ha mencionado, implica un conjunto de aspectos propios, diseñados en y para la escuela, cuestión que desborda las clásicas exigencias disciplinares y científicas, aunque no las desconoce.

El hacer escolar aludido es menor a la configuración histórica de la especificidad de la enseñanza de las ciencias sociales, que concierne a la conceptualización de las disciplinas y los saberes escolares, documentado con suficiencia en el país por autores como Alejandro Álvarez (2013) y Orlando Silva (2018), entre otros. Para Silva (2018), el concepto foucaultiano de umbrales de saber permite distinguir una forma de conocimiento distinto al científico, surgido en el marco de los sistemas educativos modernos, que históricamente ha contado con fuertes bases institucionales en la administración pública de la escuela, en tanto dispositivo de gobierno de la población. Para el autor, la configuración del campo de los saberes escolares en Colombia pasa por la profesionalización como producto de la implementación de "políticas de formación de maestros y docentes bajo las formas institucionales de escuelas normalistas (finales del siglo XIX) y facultades de educación (a partir del tercer decenio del siglo xx)" (p. 85). Así, la conflictiva confluencia histórica de enunciados, normas, decretos, leyes, burocracias, debates públicos, regulaciones, noticias, prescripciones, instituciones, producción académica, profesionalización, recomendaciones, empleos, opiniones, etc., en cuanto registros de acontecimientos de saber y poder sobre el quehacer docente y escolar, perfilan la emergencia de un discurso no homogéneo que habilita la nominación de saber escolar, entendido como un campo de luchas y tensiones por imponer significaciones y orientaciones, y por posicionar la legitimidad y validez de lo que debe ser la escuela, el docente, su formación y el conocimiento oficial escolar.

\section{Artes del hacer en la enseñanza de las ciencias sociales}

En aras de avanzar en la consideración que estimula el estatus de enseñanza de las ciencias sociales escolares como un saber y quehacer escolar particular, y con una entrada complementaria a la descrita hasta ahora, a continuación se esbozan algunos componentes que profundizan en la especificidad que implica este hacer en la interacción escolar en un contexto específico, como un aporte a la dimensión oculta del código disciplinar, esto es las prácticas docentes, aspectos que vienen siento abordados por algunos programas de formación de docentes en el país, no como elementos aleatorios del quehacer docente, sino como núcleo que atañen a la profesión. ${ }^{1} \mathrm{La}$ exposición de estas aristas, cuya idea original es retomada de María Paula González (2018), se presenta a continuación como una sistematización de observaciones, diálogos, lecturas y experiencias personales, y son ilustradas en el presente escrito por relatos de docentes a propósito de la enseñanza del pasado reciente tratados en una investigación terminada (Arias, 2018), en su momento centrada en presentar las prácticas docentes ocupadas por tratar el tema de la violencia política en clase de sociales de educación básica y media. En otras palabras, considero que los propósitos pedagógicos, la contextualización del saber, los estudiantes, los recursos, las políticas educativas y la biografía configuran aspectos clave del quehacer del docente de ciencias sociales. Estos elementos se profundizan a continuación.

Inicialmente, existe un conjunto de propósitos que la enseñanza de las ciencias sociales contempla más allá de los objetivos propiamente disciplinares, y que la literatura sobre el tema suele reducir a la confrontación de los aspectos románticos e ilustrados (Carretero, 2007). Esta reiterada tensión indica que, recientemente, las tradicionales intenciones nacionalistas del siglo XIX y principios del XX chocan con los reclamos científicos a las que se ha visto impelido el saber escolar de las ciencias sociales; sin embargo, es claro que en las últimas décadas nuevos propósitos son invocados para la dinámica escolar, como la formación ciudadana, la educación ético-política, el cuidado medioambiental y la conciencia crítica, entre otros.

En una investigación reciente (Arias, 2017), encontré que un grupo de docentes de Bogotá y municipios aledaños invocaban en su práctica docente

1 Las prácticas vienen siendo visibles gracias a la sistematización de relatos de vida de profesores, estrategia metodológica por la que se opta en el presente ensayo. Aunque existen publicaciones que recuperan las experiencias de docentes desde sus propias voces (Moreno, 2007; Murillo, 2008), pocas se centran en la experiencia de la enseñanza de las ciencias sociales (Castillo et al., 2002) y menos desde la perspectiva de historia de vida (Goodson, 2004) cuyo foco está en la genealogía del contexto, es decir, en el diálogo de testimonio con el contexto sociohistórico en el que emerge el relato biográfico. 
tres tipos de propósitos: científicos, en el sentido de enfatizar la importancia del conocimiento disciplinar dependiente de la geografía y la historia; axiológico, en cuanto muchos docentes priorizaban la formación en valores y de la estructuración moral; y político, bajo el entendido que algunos profesores dicen centrar su quehacer en la educación para la participación política y la transformación social.

En consecuencia, es posible afirmar que las ciencias sociales escolares no cargan un carácter unívoco al momento de definir sus objetivos pedagógicos a lo largo del tiempo, ni cuentan con un consenso respecto a su razón de ser, pues su condición de campo de saber confronta diferentes reclamos respecto a su horizonte, sino que la intencionalidades pedagógicas son invocadas en función de intereses de variada índole, que recientemente tienen en las políticas educativas y en el conocimiento disciplinar fuertes vectores de incidencia. A manera de ejemplo, a continuación se presenta un relato de una profesora de ciencias sociales en respuesta a la pregunta por sus propósitos formativos al abordar el conflicto armado como tema de clase:

Yo soy muy dada siempre a que todo lo explico, todo con detalle, de dónde partió, cuál es su origen. A los estudiantes los mando generalmente a consultar todo el contexto histórico, de dónde surgió, por qué se dio, y desde ahí es que se abordan los temas. Pero si son polémicos, estos temas se deben abordar con ellos, porque es la realidad del país y a ellos hay que hacerlos conscientes de que tienen un país que deben cambiar. No es solamente verlos allá como en la burbujita, aisladitos y que no se enteren de lo que pasa, no, es parte de lo que tienen que vivir y ellos de hecho viven en esos contextos. Ellos llegan a contar cómo a uno de sus amigos o algún conocido del barrio se lo llevaron, no volvió, no saben de él. Entonces, eso hay que mostrárselo, hay que trabajarlo con ellos. Mostrarles que la educación es una opción, que si ellos quieren cambiar su estilo de vida, mejorar su vida, su calidad de vida, es estudiando, es leyendo, o es siendo partícipes de los procesos que tienen a nivel de colegio y a nivel de comunidad. [...] El objetivo siempre ha sido que ellos estudien, que ellos se formen como sujetos de derechos, como sujetos políticos. En el área estamos enfocados en eso, que ellos se vuelvan sujetos políticos, que se vuelvan líderes, en que ellos tienen que incidir en la toma de decisiones, en que ellos no pueden dejar de lado lo que está sucediendo y deben ser partícipes. De hecho, ya lo vivieron, el colegio tuvo una toma y fueron los estudiantes los que se tomaron el colegio y de ahí empezó a cambiar un poquito esa manera de ver que es "yo no participo, yo no opino". Ahí está cambiando y ese es el objetivo. Mi objetivo es ese. (Gina) ${ }^{2}$

La profesora del relato anterior tiene como objetivo la formación del sujeto político y para ello da ejemplos y toma situaciones del contexto, porque quizá siente que el sentido de su tarea pedagógica debe dar respuesta a las demandas respecto a la violación de derechos humanos y al liderazgo que debe suscitar en sus estudiantes para que asuman su realidad.

Para Pérez (1992), existen cuatro modelos respecto a los propósitos de la enseñanza: la transmisión a las nuevas generaciones del cuerpo de conocimientos disciplinares; el entrenamiento en habilidades y capacidades formales independientes de los contenidos; el fomento del desarrollo natural y espontáneo del ser humano sin mayor intervención docente; $y$, finalmente, la enseñanza centrada en la generación de cambios conceptuales, en el sentido de buscar la cualificación de las estructuras formales de pensamiento.

En definitiva, la enseñanza de las ciencias sociales y de la historia está atravesada por unos propósitos pedagógicos que se establecen en función de la formación deseada para los estudiantes y que cambia con las coyunturas y los sujetos con los que el docente interactúa. También, los propósitos materializan las opciones básicas de este, y aunque dichos objetivos no siempre se logren, sí configuran el querer ser de la enseñanza y una fuerza que jalona el sentido formativo de la educación. Los propósitos despliegan la formación la persona proyectada y, por tanto, carga inevitablemente un ideal de futuro y delinea un tipo de sociedad deseada, por ello, su esencia política.

A diferencia del conocimiento científico, que pretende una responsabilidad con la verdad, con el conocimiento verificable y una correspondencia con las fuentes, cuya coherencia se intenta salvaguardar de la subjetividad del investigador, el propósito educativo del docente de ciencias sociales es más explícito en su sesgo y se establece en pro de los estudiantes con quienes se relaciona. La formación del sujeto que con frecuencia se exhibe no es más que el esfuerzo por aprovechar los múltiples accesorios culturales del que el docente echa mano en la búsqueda porque las personas que tiene a su cargo se transformen.

2 Este y los relatos que siguen fueron tomados de una investigación (Arias, 2018) con un objetivo diferente al esbozado en el presente escrito. 
El segundo aspecto que particulariza la enseñanza de las ciencias sociales escolares y que se conecta con el anterior, consiste en la importancia de contextualizar el saber. Los profesores cuentan que es supremamente importante identificar el medio en el que se trabaja, no solo en lo concerniente a los estudiantes (aspecto que se tratará más adelante), sino para establecer la pertinencia de los temas a tramitar en relación con la realidad institucional, local y nacional. No es lo mismo dar clase en primaria que en bachillerato, en una institución pública que en una privada, y siendo privado no es igual un colegio confesional a uno laico. Es diferente enseñar en una institución obsesionada por las evaluaciones que en una cuyo PEI apunta al arte. No es igual estar en un medio rural que en uno urbano. Las expectativas, los padres de familia, el contexto sociocultural y los escenarios de acción son diferentes y, por tanto, reclaman del profesor o profesora respuestas distintas.

Con frecuencia coyunturas políticas, sociales o culturales de carácter local o nacional forman parte de la lectura del contexto que el docente hace y, que por tanto, capitaliza para hacer significativas sus lecciones. Hablar de pobreza, hambre o abandono no es igual a quien lo padece y a quien no. Enseñar temas vinculados a la violencia política en medio de una comunidad que ha visto esporádicamente este drama por televisión es diferente que presentarlo en una escuela afectada directamente por el conflicto, y que exige, por tanto, cuidado y tacto por parte del profesor para ser abordado, en el caso de que sea posible hacerlo. A continuación un relato que plantea este dilema:

Nosotros casi no tratamos los temas de violencia. Además que el contexto de ellos es violencia, entonces meterles el mismo asunto es como repetirles el casete, otra vez lo mismo, repitan. De alguna manera se utiliza la otra estrategia de ojalá no se acuerda de dónde vive usted para que no lo repita. [...] El colegio queda sobre la zona plana, arriba el Centro Cultural, de la Casa de la Cultura, pero los estudiantes vienen de todos los sectores altos, entonces son sectores que tienen cierto problema de violencia, violencia juvenil de atraco, de "mataron a mi amigo", de ese tipo de cosas. Entrarles a hablar de violencia es como repetirles lo mismo que ellos viven todo el tiempo. En mi parecer, se los satura más. (Nubia)

La profesora del fragmento anterior interpreta el contexto y toma decisiones respecto a qué contenidos es posible o no enseñar. A los ojos de un científico social es imperdonable que a un estudiante a determinada edad no se le haya explicado tal o cual contenido, pero es al docente al que le toca lidiar con las condiciones del medio, cruzar las diferentes necesidades y establecer no solo qué quiere sino qué puede enseñar. Además, todo docente sabe que fruto de la contextualización de su quehacer, dedica la mayoría de su tiempo a crear ambientes favorables en el sentido resolver inicialmente asuntos lejanos a la construcción específica del conocimiento, como la convivencia o los conflictos de grupo, entre otras cosas, porque hace rato la escuela dejó de ser base depositaria del conocimiento (Martín-Barbero, 2002) y porque, desafortunadamente, la escuela tiene que resolver múltiples afugias sociales (Corea y Lewkowitz, 2000).

Gimeno Sacristán (2013) alerta sobre las fuertes transformaciones culturales de los últimos años que replantean el quehacer docente en los siguientes términos:

[...] No podemos dejar de ocuparnos del papel que juegan las lenguas extranjeras en las sociedades modernas globalizadas. No podemos pasar por alto que ha habido una transformación radical de las relaciones en la familia (¿qué familia?) y que ese fenómeno tiene una proyección no neutra en las actitudes y comportamiento del alumnado. No podemos ignorar que las nuevas tecnologías han penetrado en la vida de los menores por vías que no son las escuelas y no sabemos muy bien cómo integrarlas. No se debe quitar importancia al papel que cumplen los medios de comunicación para presentar y ocultar el mundo. No podemos abandonar a quienes son inmigrantes procedentes de otras culturas. (p. 178)

La enseñanza de las ciencias sociales escolares no cuenta con dispositivos neutrales y universales de aplicación, por el contrario, en busca de su pertinencia, se encarna en contextos específicos que el docente interpreta, y que funge a la vez como filtro para seleccionar temas, escoger ejemplos, establecer analogías, plantear contrastes y comparaciones. El contexto escolar habilita énfasis, y por qué no, explica omisiones. Un docente experimentado sabe que lo que le resultó exitoso en un colegio donde trabajó en el pasado no necesariamente le funciona en la actualidad, o lo que le sirvió en un curso no siempre lo es para el de al lado, porque el contexto mutó. Mientras un científico social comparte sus hallazgos en un mismo formato (quizá con pequeñas variaciones) en múltiples auditorios, un profesional de la educación construye tantos ambientes de aprendizaje como cursos imparte en aras de contextualizar su saber. 
La tercera característica, insinuada en el ítem anterior, que aporta a la comprensión la naturaleza de la enseñanza de las ciencias sociales escolares es la importancia de los estudiantes, en cuanto destinatarios del hacer pedagógico. En este nivel, el conocimiento de las culturas infantiles y juveniles es un aspecto que atraviesa el saber escolar, pues la enseñanza de la historia y las ciencias sociales puede quedar en mera erudición si no se piensan los lenguajes, las sensibilidades, los niveles y las expectativas de aquellos escolares que interactúan con este tipo de conocimiento.

La relevancia de los nuevos medios tecnológicos como configuradores de nuevos códigos culturales, las crisis generacionales, las ventajas digitales, los problemas de socialización, las comunicaciones emergentes, los nuevos escenarios de (des)encuentro son solo algunos de los enclaves que signan a los niños y jóvenes contemporáneos que asisten a las aulas y que un docente de ciencias sociales es convocado a conocer.

$¿$ Qué hacer con unas generaciones para las que la escuela, como metáfora de ascenso social, ya no es válida? (Garay, 2018) ¿Qué lugar tiene la escuela para unos estudiantes que privilegian su asistencia a ella únicamente como espacio de socialización? ¿Qué hacer en una escuela pública confinada al hacinamiento y al desfondamiento por la intromisión de problemáticas sociales que otras instituciones estatales desatienden? (Corea y Lewkowitz, 2000). Isabelino Siede (2007) lo expresa en los siguientes términos:

\section{Quienes transitamos las últimas décadas de la historia nacional sentimos que para vivir aquí hay que tener el cuero duro, y más aún para representar a la generación adulta en el proceso de transmisión educativa. En un contexto de instituciones frágiles y exclusión de vastos sectores de la población, la escuela ha sido, en muchos casos, la única cara visible del Estado, la que queda para recibir el cachetazo. (p. 237)}

El quehacer de la enseñanza de las ciencias sociales sucede en escuelas que están inmersas en una sociedad que, como la colombiana, es profundamente inequitativa, conflictiva, desigual e injusta. Problemas de motivación, de interés, de ilusión y de convivencia son la carta diaria en muchas aulas del país, para los que el docente no tiene respuesta, pues la naturaleza de estos conflictos atañe a la atmósfera social que viven los sectores excluidos y a una cultura política asentada por años (Herrera, Pinilla, Díaz e Infante, 2005).
Adicionalmente, es importante identificar las predisposiciones temáticas y afectivas que los escolares guardan hacia las temáticas a tratar. El siguiente relato postula el dilema al que una profesora se enfrenta al tratar estas restricciones:

El año pasado, por ejemplo, hubo que cortar el tema del inicio de la guerra civil en Colombia. Yo les contaba que tengo una anécdota de que había un guerrillero que me prendió la viruela (yo fui de las últimas en Colombia en tener viruela). Pero entonces, cuando un niño de la clase empieza a llorar y a convulsionar, obviamente paré la clase, yo no me imaginé que había sido por eso, pero lo acompaño a tomarse una aromática, me siento a hablar con él y me dice: "Es que yo no quiero que hable de armas”. Yo le dije: “¿Por qué?”. “Es que yo vi morir a mi hermana porque no se quiso ir con un guerrillero". Entonces, ahí inmediatamente abandoné el tema. (Esther)

La profesora, en el anterior relato, no solo recorta el tema organizado por la intempestiva reacción de un estudiante, sino que debe atender su situación personal ante el drama que cuenta. Este aspecto recalca que la enseñanza de las ciencias sociales, en cuanto práctica social, se dirige a unos destinatarios que imponen un quehacer particular, pues esta interacción con grupos humanos heterogéneos procura atender un conjunto de aspectos no siempre planeados, que paradójicamente forman parte de la cotidianidad, como desarrollar una clase diferente a la organizada, estar alerta a los cambios en el clima social del aula, alentar la participación, improvisar en el camino, reconocer a cada estudiante, leer los conflictos presentes y anticipar los futuros, retomar lecciones pasadas, reforzar las habilidades básicas de lectura y escritura que supuestamente son terreno conquistado, etc. Estos elementos, fundamentales en el hacer diario de la enseñanza, quizá no resulten tan relevantes a quien está obsesionado por la objetividad del conocimiento académico, cuyo centro de gravedad lo constituye la validez de los conceptos y la aplicación aséptica de teorías propias de su disciplina.

Para Davini (2015), "los alumnos son individuos heterogéneos entre sí, en sus estilos, modos de interacción, capacidades, intereses, así como en las situaciones personales o familiares que transitan" (p. 99). Como grupo, para la autora, los estudiantes conforman un sistema social sinérgico en el que lo personal y lo colectivo son polos de un mismo continuo, lo que requiere el armado de ambientes colaborativos para garantizar la enseñanza. 
Las ciencias sociales y la historia impartidas en escuelas de educación básica y media (especialmente públicas) no es un ejercicio personalizado, sino que se efectúa mayormente en medio de la interacción de colectivos numerosos de estudiantes que asisten el aula con sus mundos a cuestas. El reconocimiento de sus valores, prejuicios, expectativas, sensibilidades y sueños implica un saber cultural y un vínculo emotivo de los docentes del área con sus estudiantes, sin el cual esta práctica escolar reduce ostensiblemente sus posibilidades. Aspectos frente a los cuales muchos docentes no tienen las herramientas suficientes para desenvolverse y que representan un enorme desgaste emocional.

Un cuarto componente clave de la enseñanza de las ciencias sociales escolares que se suma a los anteriores, atañe a los recursos y estrategias didácticas usadas en las clases para generar aprendizajes y para ilustrar, afianzar o problematizar los contenidos. Libros de texto, carteleras, videos, talleres, lecturas, audios, debates, foros, exposiciones, entre otros, no son un simple decorado de la rutina escolar, ocupan la mayoría del tiempo y el espacio del trabajo en el aula. Aunque dichos recursos deben estar supeditados a los propósitos para evitar la mirada instrumental que reduce la didáctica de las ciencias sociales a los procedimientos, un mal uso de estas estrategias metodológicas o su total ausencia con frecuencia dejan hueca la práctica escolar. La habilidad del profesor o profesora para generar preguntas, para provocar nuevas lecturas de los hechos, para contrastar fuentes, para suscitar posicionamientos, para develar intereses, para generar miradas estructurales de larga o corta duración, encuentran en los materiales pedagógicos que se diseñen para el trabajo en clase un gran aliado o un insalvable obstáculo.

Un relato en la dirección de los recursos pedagógicos como buenos apoyos:

Aquí hace varios años, con otro profesor, en un momento como de locura nos inventamos unas cosas que eran "Los mundos del conflicto" y eran todos los escenarios de representación (yo tengo una galería fotográfica espectacular) de todas las cosas que hacíamos. Entonces, era responder cuál era el horizonte político de los paramilitares, y luego qué hacía la guerrilla, qué hacía el Estado y esos salones los decorábamos completamente y hacían las puestas en escena de masacres, violaciones, e inclusive hacíamos recurrir a la misma memoria de los estudiantes y de sus familias, que dibujaran de qué lugares eran y que sientan que el país los está tocando, es decir, que los hechos que están sucediendo fuera de su entorno son hechos que los influyen, que los tocan. [...] Fue un trabajo muy significativo, muy chévere, que tiene mucho reconocimiento dentro de los estudiantes, que cada año preguntan por él: "Bueno, ¿cuándo vamos a hacerlo?". Además, porque les gustaba el ejercicio de "este año hice yo tal postura, el siguiente año voy a hacer tal otra y el siguiente año quiero apostarle a tal otra", y hacer su propio trabajo de consulta, de investigación, de representación. (Oswaldo)

De acuerdo con el anterior fragmento es evidente que en los últimos años viene siendo utilizada la historia oral, las imágenes visuales y las salidas pedagógicas hacia el contexto como estrategias para provocar aprendizajes pertinentes y compromiso de los estudiantes con sus comunidades (Castaño y Velasco, 2002). Así, la enseñanza de las ciencias sociales y la historia se hace en y por medio de ciertos recursos materiales escolares que fungen como cajas de herramientas pedagógicas sin las cuales este saber escolar difícilmente sería posible.

Para Davini (2015) la administración de la clase no solo tiene que ver con el tiempo y el espacio escolares, sino con la optimización de recursos como soportes para dinamizar las clases, pues estos tienen la potencia de "ofrecer distintos modos de representación del conocimiento" (p. 101); es decir, permiten identificar las diferentes materialidades por medio de las cuales el saber se produce, asume y circula, así como los distintos lenguajes de los que se han servido los grupos sociales relacionarse con el conocimiento.

A diferencia de las ciencias sociales disciplinares que exponen sus reflexiones en documentos y en tesis formalmente escritas para ser confrontadas en una comunidad de expertos, la enseñanza del saber escolar, aunque también incluye la narrativa escrita, privilegia otros medios en su representación, pues se juega en una puesta en escena diaria y delimitada en el tiempo y el espacio, en medio de pequeños grupos humanos con instrucciones, hojas, imágenes, carteleras, diapositivas, preguntas y respuestas, lecturas en voz alta o silenciosas, individuales y colectivas; también en libros de texto, fotocopias, explicaciones, refutaciones, excursiones, ilustraciones y documentales. En la línea de plantear la diferencia con el saber académico, Chervel (1991) afirma que, a diferencia del profesor de escuela, el profesor de universidad transmite directamente su saber, pues sus prácticas concuerdan con sus objetivos, aquí "el profesor ignora en este caso la necesidad de adaptar a su público contenidos de difícil acceso y también la de modificar dichos contenidos en función de las variaciones de su público: en esta relación pedagógica, el contenido es invariable" (p. 70). Además, según el autor, 
[...] todos los problemas de enseñanza que pueden plantearse aquí se reducen a problemas de comunicación, siendo como mucho de orden retórico. Y todo cuanto se espera del alumno es que "estudie" la materia de que se trate hasta dominarla y asimilarla. (p. 70)

Los recursos y estrategias de la educación básica no solo son objeto de consumo recurrente en el aula, también sirven de plataforma de producción de saber de docentes y estudiantes que, con diferentes grados de profundidad y complejidad, aportan con sus elaboraciones a la comprensión de la realidad social e histórica en el mundo escolar.

Un quinto elemento que aporta a la especificidad del saber escolar sobre las ciencias sociales y la historia es la normativa educativa al respecto. Es decir, mientras otros tipos de conocimiento se relacionan epistemológica y metodológicamente con unas reglas de juego al margen de lo que estipula el Estado o este no traza directrices claras sobre su funcionamiento, la enseñanza de las ciencias sociales mantiene una tensión constitutiva con las políticas educativas, para el caso colombiano, con los Lineamientos curriculares (MEN, 2002), los Estándares básicos de competencias (MEN, 2004) y el último documento en construcción sobre los llamados Derechos básicos de aprendizaje (MEN, 2017) y sus mallas, sumado a otras cátedras y proyectos transversales de obligatorio cumplimiento, además de los documentos que regulan la formación docente en las universidades. Por otro lado, también están las evaluaciones masivas nacionales (MEN, 2003) e internacionales con las cuales aparentemente de miden los aprendizajes escolares en diferentes grados y niveles. Si bien esta constelación de decretos, leyes y mediciones hechas para las ciencias sociales enseñadas no reflejan mecánicamente lo que sucede en las aulas, son un insumo que el docente no oblitera en su práctica cotidiana.

La imposición de unos contenidos legítimos demandados desde el Estado es un referente ante el cual el docente toma posición, bien para acoger y reproducirlos, bien para rechazar o complementarlos. Algunas instituciones educativas exigen que el docente de ciencias sociales se pliegue totalmente a estas orientaciones, en tanto las clasificaciones anuales provenientes de evaluaciones censales definen su prestigio y su capacidad de oferta en el mercado educativo, otras disponen su propio horizonte e invitan a que los colectivos docentes construyan su propia propuesta, algunas otras generan situaciones mixtas, intentando responder a las políticas oficiales $y$, a la vez, dando espacio a iniciativas propias. En fin, independientemente del impacto que estas consignas tengan en la realidad educativa de cada aula, constituyen un foco frente al cual inevitablemente el docente es interpelado a relacionarse.

El relato que sigue expresa la manera como un profesor de ciencias sociales entiende las políticas educativas, apropósito de temas controversiales.

\begin{abstract}
Ahora a uno le exigen unos Lineamientos Curriculares básicos que son unos Estándares [sic], se supone que te dicen desde el Ministerio: "Esto debes enseñar". Luego, tú miras cómo amoldas los Estándares a tu formación y a tu proceso. Algunos compañeros se valen de textos de colegio, artículos, revistas y otro tipo de cosas. En muchos casos, uno tiene la planeación de hace muchos años, entonces lleva la lógica más o menos de lo que debe dictar; en sexto, por ejemplo, dictas Antiguo Continente, primeras civilizaciones, luego vienes en séptimo con historia de los continentes y otra vez vuelves a repasar cosas de geografía. Ese es el gran problema que uno tiene en ciencias sociales y es un mal componente entre historia y geografía, entonces no se logra hacer la distinción entre qué es historia y qué es geografía. Entonces tú tienes que jugar con los tiempos, sobre todo a partir de qué es lo que más te gusta, si te gusta más la geografía vas por temas de geografía y dejas siempre la historia rezagada, o si eres más de historia, lo contrario. (Oswaldo)
\end{abstract}

El profesor amolda las políticas a su formación y a su propio proceso, también a sus gustos y afinidades personales. A diferencia de otras profesiones, las ciencias sociales escolares en el país son fuertemente reguladas en casi todos sus niveles (educación básica, media y formación de licenciados), con políticas que prescriben abiertamente los contenidos a impartir y con las correspondientes evaluaciones para todo el proceso de formación (pruebas Saber $3^{\circ}-5^{\circ}-9^{\circ}-11^{\circ}$, Pre-Saber $11^{\circ}$, Validación del bachillerato académico, Saber TyT, Saber Pro, Saber Pro exterior, de ingreso a la carrera docente, de ascenso en el escalafón) (Arias et al., 2018). Esto sucede porque hace décadas los sistemas educativos nacionales vienen siendo objeto de intervención por parte de organismos internacionales centrados en el discurso del capital humano $y$, por ello, interesados en armonizar los diferentes estratos educativos con la lógica del mercado, el emprendimiento y la autogestión (Laval, 2004), asunto al que las políticas sobre la enseñanza de lo social e histórico no son ajenas.

Para Jairo Gómez (2015) los docentes de ciencias sociales del país poco referencian en la sistematización de sus prácticas los documentos de política pública educativa, 
[...] lo cual pondría en evidencia que la gran mayoría aún considera que historia y geografía son áreas por antonomasia de las ciencias sociales, en oposición a los lineamientos vigentes que tienen un carácter más interdisciplinario, o que prefieran más los lineamientos institucionales. (p. 27)

Este hecho, empero, no implica desconocer que para algunos docentes constituyen el eje de su práctica o que en las planeaciones institucionales es un tema que aparece vinculado. Al respecto, se pregunta Isabelino Siede (2002) “ ¿no será inherente a la tarea docente estar siempre en contradicción con el mismo 'sistema' que integramos? ¿No será parte de la tarea educativa mantener siempre abierta la disputa por las condiciones materiales y simbólicas de nuestro trabajo?" (p. 236).

El último aspecto considerado en el presente escrito consiste en la biografía docente. Bajo el entendido que la enseñanza de las ciencias sociales cuenta con un elemento clave que la particulariza y ello es la trayectoria, vivencias y opciones que son parte de la vida del docente que imparte esta asignatura.

Un relato en esta dirección:

Alguien me decía que uno no podría ser profesor del Distrito si no había sido "ñero", y yo decía: "Sí, pero usted tampoco puede ser profesora de sociales, si no ha militado en alguna huevonada, porque es que esto es muy difícil aprenderlo mirando por la ventana". Entonces, lo que me lleva a mí a estudiar ciencias sociales no son inquietudes del orden intelectual ni académico, porque uno entra de primíparo a estudiar sociales y uno no sabe nada. La primera clase que me hicieron en la Universidad era Taller de Lengua, que era una vaina ahí de escritura, y yo pensé: “Uy!, pero esto de sociales es chévere”, yo pensé que eso era sociales. Pero hoy la motivación lo es la preocupación, la inquietud del orden político como tal. En la inquietud de orden político yo podría pensar que mi vida ha girado, primero, en mi juventud, desde una lógica vinculada al pensamiento anarquista. Me gustaba mucho la escuela de Ferrer i Guardia, el descreer en el mundo. Lo que pasa es que ya después me di cuenta que descreer en todo es una postura goda, en el sentido que lleva al quietismo. Luego una vinculación con las miradas que desde América Latina se han tenido con el mundo, la idea de construcción de poder popular. Es decir, la idea de construcción de poder popular pero que no es sinónimo del pueblo en armas, así que me parece que el poder se construye desde referentes de asociatividades, pero estos referentes no pueden estar en el plano de lo doctrinal, sino que vuelvan otra vez al plano de la comprensión del mundo. (Antonio).
El fragmento del profesor Antonio establece la importancia de mirar la relación entre las trayectorias individuales y la profesión docente, específicamente, en la enseñanza de las ciencias sociales. Con este ejemplo no se quiere universalizar la posición de compromiso sociopolítico y el quehacer docente, quizá válido para algunos, sino ahondar que la trascendencia de la experiencia, la trayectoria y la biografía como ser humano, se pone en juego en el instante del quehacer del docente de esta área.

Dice Larrosa (2006) que la experiencia, "eso que me pasa” (p. 88), implica varias cosas: en primer lugar, un acontecimiento extraño que afecta; pero también, un impacto subjetivo por cuanto "me afecta a mí, tiene efectos en mí, en lo que yo soy, en lo que yo pienso, en lo que yo siento, en lo que yo sé, en lo que yo quiero" (p. 90), de aquí que las experiencias transformen; y también significa algo que deja huella, rastro, herida, que no me deja igual.

La experiencia del docente, su camino y su vida vivida dejan huellas en su quehacer. Aparecen en su práctica destellos de sus opciones, marcas de sus pensamientos más preciados; en lo que pasa en el aula hay vestigios de su pasado. La enseñanza de las ciencias sociales y la historia encuentran en esta dimensión biográfica, de nuevo, otro fuerte sesgo subjetivo, pues es la palabra y el gesto cotidianos de maestros concretos los que llevan este hacer al aula. Esta dimensión subjetiva de la práctica docente implica posturas cognitivas, morales, estéticas, éticas y políticas que consciente o inconscientemente le dan forma al saber escolar propio de las ciencias sociales en el aula, quehacer que, paradójicamente, pretende formar posturas y posicionamientos en los estudiantes. Dado que la materia prima de las ciencias sociales escolares está referida al devenir de la cultura, la historia y la sociedad, es la experiencia misma del docente objetivada como materia de enseñanza la que se lleva al salón de clase, por momentos revestida de conocimientos sociales. El docente de ciencias sociales porta una cosmovisión cuyos colores, olores, sabores y matices afectan el matiz de sus explicaciones y el carácter de su discurso.

\section{Cierre parcial}

He mencionado hasta el momento algunos hitos históricos sobre la enseñanza de las ciencias sociales en Colombia, igualmente he enfatizado en la importancia de considerar la historia y las ciencias sociales escolares como un saber y un quehacer práctico, cuyo estatuto propio concita perspectivas que trascienden el restringido canon disciplinar; además, he descrito 
algunas aristas de este hacer escolar que contribuyen a configurar el sentido cognitivo y performativo que tiene el quehacer del docente de ciencias sociales e historia, como son los propósitos, los recursos, el contexto, la condición estudiantil y docente, y finalmente, el aspecto normativo.

No se trata de desechar el conocimiento científico en la escuela sentenciando que este no tiene sentido en las aulas. Por supuesto que la docencia de las ciencias sociales comporta la apropiación de elementos conceptuales y estructurales de las disciplinas, vinculados a la tradición cultural que contribuyen a la comprensión del medio local, nacional e internacional. Lo que resalto es que dichos contenidos se recrean, complementan y supeditan permanentemente en función de unas necesidades escolares distintas a aquellas que les dieron origen y que, por tanto, sufren una especie alquimia escolar, al decir de Popkewitz (2000), que modifica tradiciones intelectuales en prácticas docentes. $^{3}$

Por otro lado, no se trata de idealizar la práctica y el hacer docentes, induciendo equivocadamente a pensar que solo se requiere formación e investigación a este nivel, o a concluir que todo aprendizaje escolar depende únicamente de la voluntad ingenua del docente, desconociendo que toda práctica social, en cuanto actividad regentada por seres históricos, está condicionada por la realidad sociopolítica que le precede, con imaginarios imperantes respecto a lo permitido, lo posible y lo deseado. Al decir de Romero (2014), tal error "tiende irremediablemente a concentrarse en las motivaciones subjetivas y en las conductas de estos agentes, a menudo en términos individualistas y autoindicativos" (p. 12). Subrayar la importancia del quehacer no significa, para el caso de la enseñanza de las ciencias sociales, indicar que todo el mundo escolar se reduce al encuentro intersubjetivo en el aula, o que el hacer encarna idealmente los auténticos postulados libertarios que anhelamos los pensadores críticos. Todo lo contrario, lo que las prácticas docentes nos dejan ver no es necesariamente una mejor escuela, tampoco una peor, sino los trazos, hasta ahora ocultos, de las intenciones, sensibilidades, miradas y dinámicas de la vida en el

3 Para el autor, "lo que aparece en la escuela como "ciencias", "matemáticas", "redacción" o "arte" presenta una vinculación muy tenue con el campo intelectual que lleva el mismo nombre, pero se trata de una construcción pedagógica que responde a las expectativas que implican el horario escolar, las concepciones acerca de la niñez y convenciones de la enseñanza que transforman el saber y la búsqueda intelectual en una estrategia de administración del "yo" que responde a la pregunta de cómo "crear" las disposiciones internas y las sensibilidades de un ser moral y ético (Popkewitz, 2000, p. 20). aula narrada en las voces de uno de sus protagonistas. Precisamente es el aspecto al que este texto, a modo de fragmento, trata de contribuir con un dibujo quizá incompleto, pues faltan muchas más voces, no solo de los propios docentes, sino de otros agentes de la realidad educativa.

Para finalizar, en el marco de lo descrito, colijo que actualmente las ciencias sociales y la historia escolares enfrentan dos importantes retos: por un lado, una lucha teórica por reivindicar este saber y quehacer pedagógico en una disputa con otros campos por imponer significados y regular prácticas; parafraseando a Olga Lucía Zuluaga (1999) que hace años denunciaba la atomización al que era sometido el discurso pedagógico en el que las ciencias humanas lo repartían cual botín, hoy se observa que organismos multilaterales, el Estado, algunos medios e intelectuales pugnan por definir qué, cuándo y cómo deber ser enseñado lo histórico y lo social en la educación básica y media. ${ }^{4}$ Pero, por otro lado, enfrenta el reto político de posicionar la palabra y la práctica del docente del área como principal responsable de este saber y hacer, posicionamiento que se da en un escenario nacional que lo desacredita, lo invisibiliza, lo precariza, lo satura y lo ningunea.

El cariz político que históricamente ha tenido la enseñanza de lo social actualmente se revela con intensidad cuando el docente de este campo es impelido a defender su estatus como productor de saber al margen y en contra de los poderes y regímenes de verdad que lo quieren encorsetar, y de las tramposas formas de participación oficial que supuestamente lo involucran, y esta tarea, como es obvio, no se puede delegar.

\section{Referencias}

Álvarez, A. (2013). Las ciencias sociales en Colombia. Genealogías pedagógicas. Bogotá: IDEP.

Arias, D. (2015). La enseñanza de las ciencias sociales en Colombia: lugar de las disciplinas y disputa por la hegemonía de un saber. Revista de Estudios Sociales, 52, 134-146.

4 Ejemplo de ello puede ser la reciente Ley 1874 de 2017 que dice restablecer la enseñanza de la historia como disciplina integrada en los lineamientos de ciencias sociales, y el Decreto 1660 de 2019 que reglamenta la Comisión Asesora de dicha Ley. De los seis integrantes de dicha Comisión solo se da cupo a un representante de los profesores de educación básica y media en ejercicio, para el cual se establecen taxativamente cinco requisitos, para los otros integrantes no se establece ninguna exigencia. 
Arias, D. (2017). Propósitos de la enseñanza de las ciencias sociales y la historia. Una aproximación desde relatos docentes. Revista Aletheia, 9(1), 18-37.

Arias, D. (2018). La enseñanza del pasado reciente en Colombia. La violencia política y el conflicto armado como tema de aula. Bogotá: Universidad Distrital Francisco José de Caldas.

Arias, D., Díaz, O., Garzón, I., León, A., Rodríguez, S. y Valbuena, É. (2018). Entre las exigencias de calidad y las condiciones de desigualdad: la formación inicial de profesores en Colombia. Bogotá: Universidad Pedagógica Nacional, Colciencias.

Bourdieu, P. y Passeron, J. (2001). La reproducción. Elementos para una teoría del sistema de enseñanza. Madrid: Editorial Popular.

Carretero, M. (2007). Documentos de identidad. La construcción de la memoria histórica en un mundo global. Buenos Aires: Paidós.

Castaño, R. y Velasco, G. (2002). Aprender historia haciendo historia. Métodos y técnicas para la enseñanza de la historia. Bogotá: Universidad Distrital Francisco José de Caldas.

Castillo, E., Cortés, J., García, L., Ortiz, A., Vélez, G., Villadiego, Á. y Rivas, A. (2002). Los maestros de ciencias sociales. Bogotá: Cooperativa Editorial Magisterio.

Chervel, A. (1991). Historia de las disciplinas escolares. Reflexiones sobre un campo de investigación. Revista de Educación, 295, 59-111.

Chevallard, I. (1997). La transposición didáctica. Del saber sabio al saber enseñado. Buenos Aires: Aique.

Corea, C. y Lewkowitz, I. (2000). Pedagogía del aburrido. Escuelas destituidas, familias perplejas. Buenos Aires: Paidós.

Cuesta, R. (2002). La historia como disciplina escolar: génesis y metamorfosis del conocimiento histórico en las aulas. En C. Forcadell e I. Peiró (coords.), Lecturas de la historia: nueve reflexiones sobre historia de la historiografía (pp. 221-252). Zaragoza: Institución Fernando el Católico.

Davini, M. (2015). La formación en la práctica docente. Buenos Aires: Paidós.

De Certeau, M. (1900). La invención de lo cotidiano. Artes de hacer (Vol. 1.). México: Universidad Iberoamericana.

Garay, L. (2018). (In-)Movilidad social y democracia. Algunas perspectivas teóricas, analíticas y empíricas a propósito de la experiencia de países de la OCDE y de Colombia. Bogotá: Desde abajo.
Gimeno Sacristán, J. (2013). En busca del sentido de la educación. Madrid: Morata.

Giroux, H. (1988). Los profesores como intelectuales. Hacia una pedagogía crítica del aprendizaje. Barcelona: Paidós.

Gómez, J. (2015). ¿Cómo enseñan los maestros colombianos en el área de ciencias sociales y filosofía? Análisis de las propuestas del Premio Compartir al Maestro. Bogotá: Fundación Compartir.

González, M. (2012). La historia de la enseñanza de la historia: un saber escolar inestable. Revista Praxis Pedagógica, 13, 56-73.

González, M. (2018). La enseñanza de la historia en el siglo XXI. Saberes y prácticas. Los Polvorines: Universidad Nacional de General Sarmiento.

Goodson, I. (2004). Profesorado e historias de vida. Un campo de investigación emergente. En I. Goodson (ed.), Historias de vida del profesorado (pp. 45-62). Barcelona: Octaedro.

Herrera, M., Pinilla, A. y Suaza, L. (2003). La identidad nacional en los textos escolares de ciencias sociales. Colombia 1900-1950. Bogotá: Universidad Pedagógica Nacional.

Herrera, M., Pinilla, A., Díaz, C. e Infante, R. (2005). La construcción de cultura política en Colombia. Proyectos hegemónicos y resistencias culturales. Bogotá: Universidad Pedagógica Nacional.

Larrosa, J. (2006). Sobre la experiencia. Revista Aloma, Filosofía de l'educació, 19, 87-112.

Laval, C. (2004). La escuela no es una empresa. El ataque neoliberal a la enseñanza pública. Barcelona: Paidós.

Martín-Barbero, J. (2002). La educación desde la comunicación. Buenos Aires: Norma.

Martínez, A. (2008). La escuela: un lugar para el común. En G. Frigerio y G. Dicker (comps.), Educar: posiciones acerca de lo común (pp. 153-172). Buenos Aires: Del Estante.

Ministerio de Educación Nacional (MEN). (2002). Lineamientos curriculares de ciencias sociales. Bogotá.

Ministerio de Educación Nacional (MEN). (2003). ¿Cómo entender las pruebas saber y qué sigue? Bogotá.

Ministerio de Educación Nacional (MEN). (2004). Estándares de competencias en ciencias sociales. Bogotá.

Ministerio de Educación Nacional (MEN). (2017). Derechos básicos de aprendizaje de ciencias sociales. Documentos en construcción. Bogotá. 
Moreno, P. (comp.) (2007). Los maestros cuentan... Experiencias de ser. Bogotá: Escuela Normal Superior Nuestra Señora de la Paz.

Murillo, G. (comp.) (2008). Maestros contadores de historias. Relatos de vida. Medellín: Gobernación de Antioquia.

Pérez, Á. (1992). Enseñanza para la comprensión. En J. Gimeno y Á. Pérez, Comprender y transformar la enseñanza (pp. 78-114). Madrid: Morata.

Popkewitz, T. (2000). El rechazo al cambio en el cambio educativo: sistemas de ideas y construcción de políticas y modelos de evaluación nacionales. Perfiles Educativos, XXII(90), 5-33.

Rodríguez, S. (2017). Memoria y olvido: usos públicos del pasado en Colombia, 1930-1960. Bogotá: Universidad del Rosario, Universidad Nacional de Colombia.

Romero, J. (2014). Conocimiento escolar, ciencia, institución y democracia. Archivos Analíticos de Políticas Educativas, 22(21), 1-36.
Saldarriaga, Ó. (2006). Del oficio de maestro. ¿De intelectual subordinado a experto subordinador? Revista Educación y Ciudad, 11, 53-70.

Siede, I. (2002). La educación política. Ensayos sobre ética y ciudadanía en la escuela. Buenos Aires: Paidós.

Silva, O. (2018). Investigar históricamente las disciplinas y los saberes escolares: el caso de la enseñanza de las ciencias sociales en Colombia. Revista Pedagogía y Saberes, 49, 81-93.

Vasco, C. (2003). Objetivos específicos, indicadores de logros y competencias: ¿y ahora estándares? Revista Educación y Cultura, 62, 33-41.

Zuluaga, O. (1999). Pedagogía e historia. La historicidad de la pedagogía. La enseñanza, un objeto de saber. Santafé de Bogotá: Siglo del Hombre, Universidad de Antioquia. 